\title{
1D Photonic Crystal With Anisotropic Defect Layer Containing Graphene-based Hyperbolic Metamaterial With a Focus on Spectral Statistics
}

Ziba Saleki ( $\sim$ ziba_saleki@tju.edu.cn )

Tianjin University

Amir Majarshin

Nankai University

Yan Luo

Nankai University

De-long Zhang

Tianjin University

Keywords:

Posted Date: March 17th, 2021

DOl: https://doi.org/10.21203/rs.3.rs-289817/v1

License: (c) (1) This work is licensed under a Creative Commons Attribution 4.0 International License.

Read Full License 


\section{Abstract}

The authors have requested that this preprint be removed from Research Square. 